\title{
KEANEKARAGAMAN KUMBANG CERAMBYCID (Coleoptera: Cerambycidae) PADA PERKEBUNAN KAKAO DI TIGA TIPE HABITAT
}

\section{Diversity of Cerambycid Bettles (Coleoptera: Cerambycidae) on Cacao Plantation in Three Different Land Types}

\author{
Rahmat ${ }^{*}$ I Nengah Suwastika dan Fahri \\ Jurusan Biologi, Fakultas MIPA, Universitas Tadulako, \\ JI.Soekarno Hatta km 9Tondo, Palu 94118, Sulawesi Tengah, Indonesia
}

Corresponding author : rbiologi@yahoo.com

\begin{abstract}
This research is to determine diversity Cerambycid beetles on cacao plantation (Coleoptera: Cerambycidae) based on three different land types. The research was carried out from June 2017 to April 2018. Sample were collected using Atrocarpus trap at three types of cocoa plantations i.e. cocoa plantation in margin of the forest (Omu Village), not cultivated cocoa plantion (Wombo Village) and cultivated cocoa plantation (Sibowi Village). Total of 381 Cerambycid beetles belonging to 5 tribes, 7 genera and 13 species were obtained during the study. The highest of diversity $\left(\mathrm{H}^{\prime}\right)$ and Eveness $(\mathrm{E})$ indices was found in the not cultivated cacao plantation (KTT). The Bray-Curtis similarity indices (IBC) was showing a similarity between cocoa plantation in margin of the forest $(\mathrm{KPH})$ with cultivated cocoa plantation (KT). The result of this study was showing that three types of cacao plantations in this research, very supported the existence of Cerambycidae bettles and hasn't significant effect on their life.
\end{abstract}

Keywords: Atrocarpus trap, Cerambycidae, Coleoptera, Cacao plantation, Diversity

\section{PENDAHULUAN}

Kumbang cerambycid (Coleoptera: Cerambycidae) merupakan kelompok serangga yang memiliki peranan penting bagi ekosistem, terutama dalam proses penguraian bahan organik (Amirullah dkk., 2014). Habitat kumbang cerambycid meliputi hutan dengan tutupan vegetasi yang tinggi maupun terbuka (Noerdjito, 2008), hutan tanaman (Kebun Raya) (Noerdjito, 2010) bahkan juga perkebunan. Beberapa laporan mengenai habitat kumbang cerambycid pada perkebunan diantaranya yaitu pada kebun karet dan kelapa sawit (Fahri et al.,
2016), kebun tebu dan jati (Sataral dkk. 2017) serta kebun cengkeh (Rafil et al., in press). Salah satu perkebunan yang berpeluang menjadi habitat kumbang cerambycid yaitu kakao.

Kakao (Theobroma cacao L.) merupakan salah satu jenis tanaman perkebunan yang banyak dikembangkan dan dibudidayakan di Sulawesi Tengah. Hingga tahun 2017, total luas areal perkebunan kakao rakyat di Sulawesi Tengah mencapai 288,986 $\mathrm{Ha}$ dengan produksi mencapai 100,649 ton (Ditjenbun, 2017). Salah satu faktor yang dapat mempengaruhi produktivitas kakao yaitu 
Rahmat, dkk. Biocelebes. Desember. 2019. Volume 13 Nomor 3, Halaman 271-278

serangan hama dari kelompok serangga, Pengambilan sampel kumbang termasuk kumbang cerambycid. Spesies dilakukan pada bulan Juni 2017 hingga April Steirastoma breve (Lamiinae: Acanthoderini) 2018, pada tiga lokasi perkebunan kakao merupakan salah satu anggota kumbang yaitu Desa Omu, Kec. Gumbasa Kab. Sigi cerambycid yang berperan sebagai hama (habitat kakao pinggiran hutan/KPH), Desa pada tanaman kakao (Liendo et al., 2010). Sibowi, Kec. Tanambulava, Kab. Sigi

Komunitas kumbang cerambycid, (habitat kakao terawat/KT) dan Desa khususnya pada perkebunan kakao masih Wombo Kec. Tawaeli Kab. Donggala sedikit dipelajari terutama pada aspek (habitat kakao tidak terawat/KT). Sampel keanekaragamannya. Karena itu, perlu dikoleksi menggunakan Artocarpus trap untuk dilakukan penelitian mengenai (Noerdjito, 2008), yang berupa cabang keanakaragaman kumbang cerambycid berdaun yang diikatkan pada batang pohon pada habitat perkebunan kakao. Penelitian ini, bertujuan untuk mengetahui dengan ketinggian 1 hingga $1,5 \mathrm{~m}$ dari permukaan tanah. Setiap lokasi dipasang keanekaragaman kumbang cerambycid pada tiga tipe habitat kakao yaitu kebun kakao terawat (KT), kebun kakao tidak terawat (KTT) dan kebun kakao di pinggiran hutan $(\mathrm{KPH})$

sebanyak 16 perangkap dengan jarak antar perangkap $\pm 20 \mathrm{~m}$. Pengoleksian sampel dilakukan dengan metode beating (memukul) perangkap dan dilakukan sebanyak 5 kali koleksi pada setiap 4 hari, yaitu pada hari ke-4, ke-7, ke-10, ke-13, dan ke-16 setelah pemasangan.

\section{BAHAN DAN METODE}

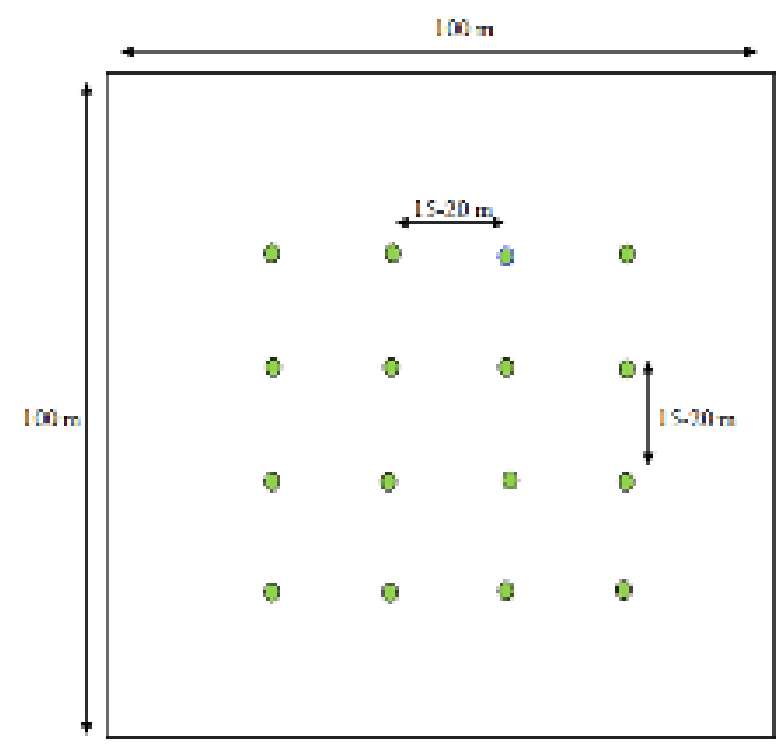

Gambar 1. Desain pemasangan Artocarpus trap pada setiap lokasi. 


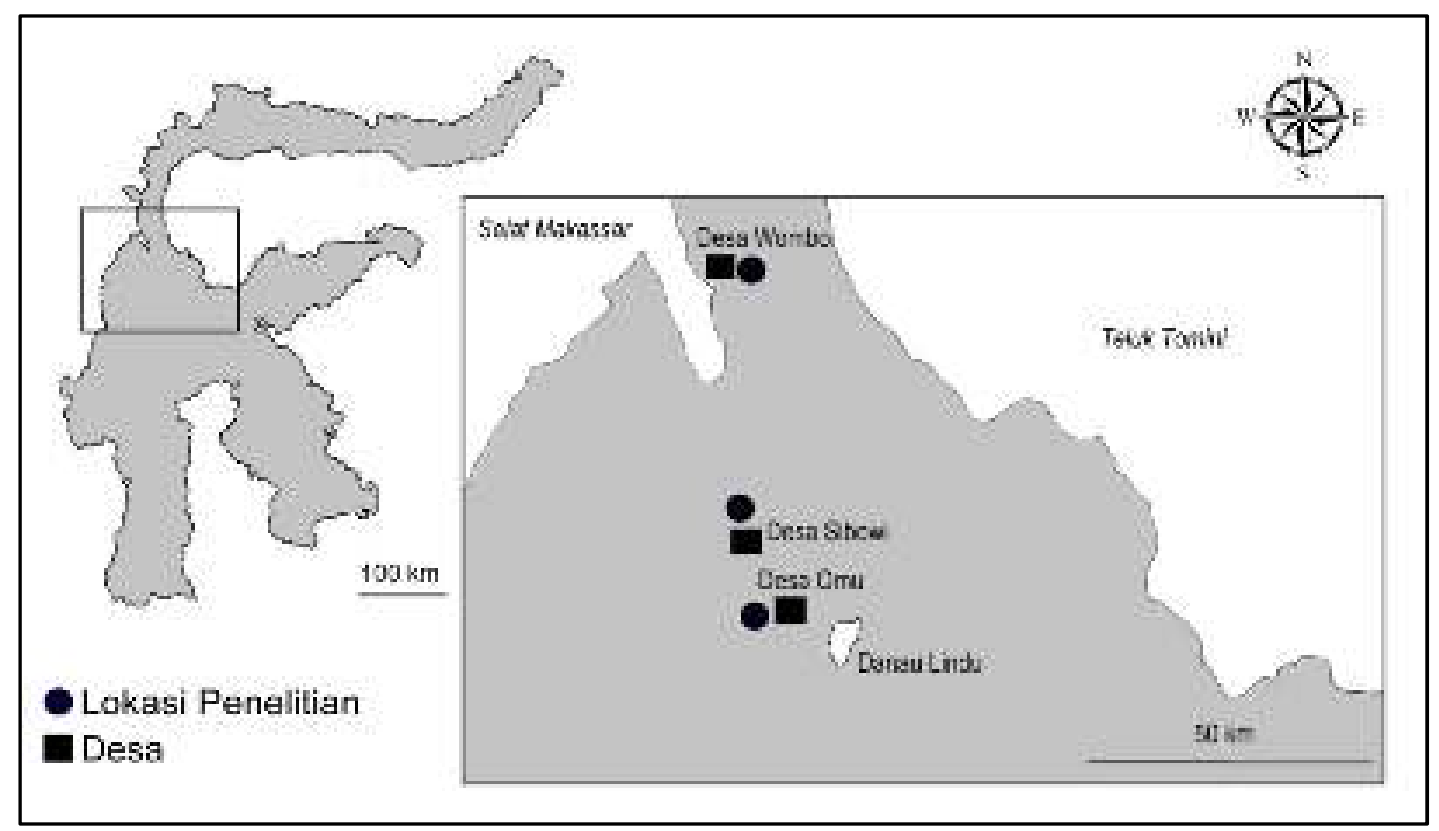

Gambar 2. Peta lokasi penelitian (Dimodifikasi dari google maps)

Sampel kumbang yang diperoleh meliputi lokasi, tanggal, bulan, tahun dan dimasukan ke dalam botol dan dibius nama kolektor. Selanjutnya, sampel menggunakan chloroform, kemudian kumbang dimasukkan dalam oven dengan dimasukan ke dalam kertas papilot untuk suhu 35 hingga $40^{\circ} \mathrm{C}$ selama 1 minggu. disimpan sebagai koleksi kering. Sebelum Sampel kemudian dipindahkan dalam identifikasi, dilakukan proses pinning freezer, juga selama satu minggu dan terhadap sampel dengan cara menusukkan kemudian dimasukkan dalam ruang koleksi jarum serangga kebagian elytra sebelah kanan. Jarum serangga yang digunakan disesuaikan dengan ukuran tubuh kumbang. Kumbang dengan ukuran tubuh $<10 \mathrm{~mm}$ ditempelkan pada ujung point (kertas segi tiga memanjang dengan ukuran panjang 8$10 \mathrm{~mm}$ dan lebar 3-4 mm). Penggunaan point dilakukan dengan cara menyentuhkan perekat pada ujung point kemudian disentuhkan kebagian abdomen sebelah kiri.

Setelah proses pinning selesai, dilanjutkan dengan proses labeling yang untuk diidentifikasi.

$$
\text { Identifikasi sampel dilakukan }
$$

menggunakan kunci determinasi Makihara and Noerdjito (2004) dan Bezark (2015). Sampel selanjutnya disimpan di Laboratorium Zoologi Jurusan Biologi FMIPA Universitas Tadulako.

Analisis data yang dilakukan yaitu meliputi indeks keanekaragaman Shanon $\left(H^{\prime}\right)$, indeks kemerataan $(E)$ dan indeks kesamaan Bray-Curtis (IBC), menggunakan program PAST versi 2.17 


\section{HASIL DAN PEMBAHASAN}

Total diperoleh sebanyak 381 individu kumbang cerambycid yang tergolong dalam 5 tribe, 7 genus dan 13 spesies (Tabel 4.1). Secara umum, spesies Pterolophia cf. affiinis, Sibra alternans, pterolophia sp 1 dan Acalolepta ruticatrix. memiliki kelimpahan yang paling tinggi. Pada habitat $\mathrm{KPH}$, spesies $S$. alternans memiliki kelimpahan paling tinggi dikarenakan banyaknya tumbuhan yang menjadi host dari spesies ini. Sataral dkk. (2017), melaporkan S.altenans memiliki sifat polifagus (memiliki lebih dari satu tumbuhan inang), sehingga ketersediaan sumber daya juga lebih banyak. Kondisi seperti ini juga didukung oleh letak $\mathrm{KPH}$ yang berada di pinggiran hutan sehingga ketersediaan makanan lebih melimpah. Beberapa spesies hanya di temukan pada satu habitat dan tidak di temukan di habitat yag lainnya seperti Acalolepta fasciata hanya di temukan pada habitat KTT, menurut Makihara and Noerdjito, (2004) Berbagai jenis kumbang Cerambycidae hanya dapat ditemukan di hutan sebagai jenis-jenis hutan dan beberapa jenis dapat ditemukan di kawasan terbuka atau hutan terganggu akibat ulah manusia (penebangan, perubahan fungsi kawasan) dan kebakaran.

Tabel 1. Daftar spesies dan jumlah kumbang Cerambycid dan jumlah individu yang dikoleksi

\begin{tabular}{|c|c|c|c|c|c|}
\hline \multirow{2}{*}{ Tribe } & \multirow{2}{*}{ Genus } & \multirow{2}{*}{ Spesies } & \multicolumn{3}{|c|}{ Habitat } \\
\hline & & & $\mathrm{KPH}$ & KTT & KT \\
\hline \multirow[t]{3}{*}{ Apomecynini } & Sybra & Sybra alternans & 52 & 3 & 23 \\
\hline & & Sybra sp.1 & 7 & 0 & 9 \\
\hline & & Sybra sp.2 & 0 & 2 & 0 \\
\hline Gnomini & Gnoma & Gnoma pulvurea & 0 & 4 & 0 \\
\hline \multirow[t]{4}{*}{ Monochamini } & Acalolepta & Acalolepta rusticatrix & 6 & 20 & 10 \\
\hline & & A. fasciata & 0 & 2 & 0 \\
\hline & Epepeotes & Epepeotes plorator & 0 & 5 & 4 \\
\hline & Pelargoderus & Pelargoderus alcanor & 1 & 3 & 0 \\
\hline \multirow[t]{4}{*}{ Pteropliini } & Pterolophia & Pterolophia cf. affinis & 16 & 6 & 79 \\
\hline & & Pterolophia sp.1 & 23 & 0 & 49 \\
\hline & & Pterolophia sp.2 & 11 & 0 & 24 \\
\hline & & Pterolophia sp.3 & 15 & 6 & 0 \\
\hline Exocentrini & Exocentrus & Exocentrus sp & 1 & 0 & 0 \\
\hline \multicolumn{2}{|c|}{ Jumlah Individu } & & 132 & 51 & 198 \\
\hline \multicolumn{3}{|c|}{ Jumlah Total Individu } & & & 381 \\
\hline
\end{tabular}



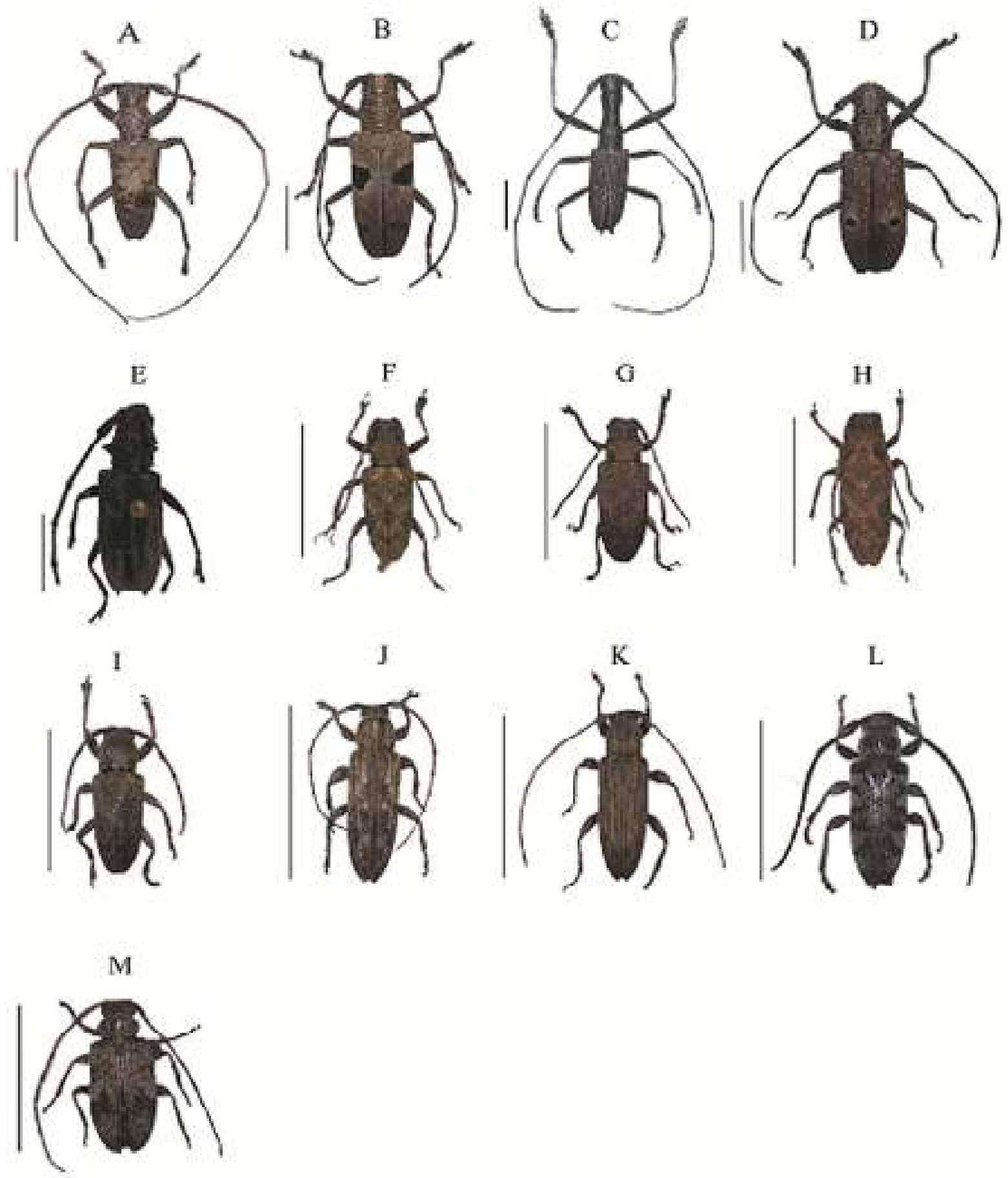

Gambar 3. Kumbang antena panjang yang terkoleksi: Acalolepta rusticatrix (A), Epepeotes plorator (B), Gnoma pulvurea (C), Pelargoderus alcanor (D), Acalolepta fasciata (E), Pterolopia cf. affinis (F), Pterolopia sp.1 (G), Pterolopia sp.2 (H), Pterolopia sp.3 (I), Sybra alternans (J), Sybra sp.1 (K), Sybra sp.2 (L), Exocentrus sp (M). Skala $1 \mathrm{~cm}$. 
Kelimpahan terendah kumbang Cerambycid terdapat pada genus Exocentrus. Selain pada penelitian ini, genus Exocentrus juga pernah dilaporkan pada perkebunan karet di Provinsi Jambi (Fahri et al., 2016). Rendahnya kelimpahan spesies ini kemungkinan bukan merupakan bukan spesies asli dari habitat ini, melainkan hanya tertarik pada Artocarpus trap.

Nilai indeks keanekaragaman $\left(\mathrm{H}^{\prime}\right)$ dan kemerataan (E) tertinggi diperoleh pada habitat KTT, jika dibandingkan dua kebun kakao lainnya (KPH dan KT) (Tabel 2). Karakteristik tipe habitat di Desa Wombo yang juga banyak ditumbuhi semak serta pepohonan (pengamatan pribadi, 2017), menyebabkan host kumbang Cerambycid lebih bervariasi. Menurut Noerdjito (2012), spesies kumbang antena panjang yang berukuran kecil, larvanya mampu hidup pada cabang atau ranting kecil dan banyak ditemukan di berbagai tipe habitat.

Tabel 2. Jumlah jenis (S), jumlah individu (N), indeks keanekaragaman $\left(\mathrm{H}^{\prime}\right)$ dan indeks kemerataan (E) pada tiga tipe habitat.

\begin{tabular}{lcccc}
\hline \multicolumn{1}{c}{ Habitat } & S & N & E & H' \\
\hline Kebun KPH & 9 & 132 & 0,64 & 1,75 \\
Kebun KTT & 9 & 51 & 0,73 & 1,88 \\
Kebun KT & 7 & 198 & 0,7 & 1,56 \\
\hline
\end{tabular}

Nilai kesamaan komunitas kumbang Cerambycid tertinggi yaitu antara $\mathrm{KPH}$ dan KT (IBC=72,357) (tabel 3 dan gambar 4). Berdasarkan komposisi kumbang Cerambycid, terdapat sebanyak 6 spesies yang ditemukan secara bersamaan pada kedua habitat tersebut (Sybra alternans,
Sybra sp.1, Acalolepta rusticatrix, Pterolophia cf. affinis, Pterolophia sp.1 dan Pterolophia sp.2). KPH dan KT memiliki karakteristik yang hampir sama yaitu terdapat ranting, kayu lapuk dan tutupan tajuk dari pohon kakao yang cukup rapat (pengamatan pribadi, 2017). Kondisi ini sangat mendukung kehadiran spesies Cerambycid. Kemiripan komposisi ini kemungkinan disebabkan oleh kemiripan karakteristik kedua habitat, sehingga komposisi individu yang ditemukan juga memiliki kemiripan. Menurut Noerdjito (2010), kondisi vegetasi pada setiap area sangat berbengaruh terhadap komposisi jenis kumbang antena panjang.

Jumlah individu yang dikoleksi pada setiap stasiun bervariasi mulai dari pengoleksian pertama hingga kelima (hari ke-4 hingga ke16). Habitat $\mathrm{KT}$, jumlah individu tertinggi yang dikoleksi terdapat pada pengoleksian pertama (hari ke-4). Dua habitat lainnya, yaitu KPH dan KTT, jumlah individu tertinggi terdapat pada pengoleksian kedua (hari ke7), disebabkan oleh perangkap Artocarpus yang mulai efektif bekerja pada hari ke-7. Pada kisaran waktu tersebut, dedaunan perangkap Artocarpus mulai layu sehingga kumbang Cerambycid lebih tertarik untuk hinggap (Fahri et al., 2016).

Kebun KTT (Desa Wombo) merupakan habitat yang sangat mendukung keberadaan kumbang Cerambycid, dibuktikan dengan tingginya nilai indeks 
keanekaragaman pada wilayah ini dibanding wilayah lain.

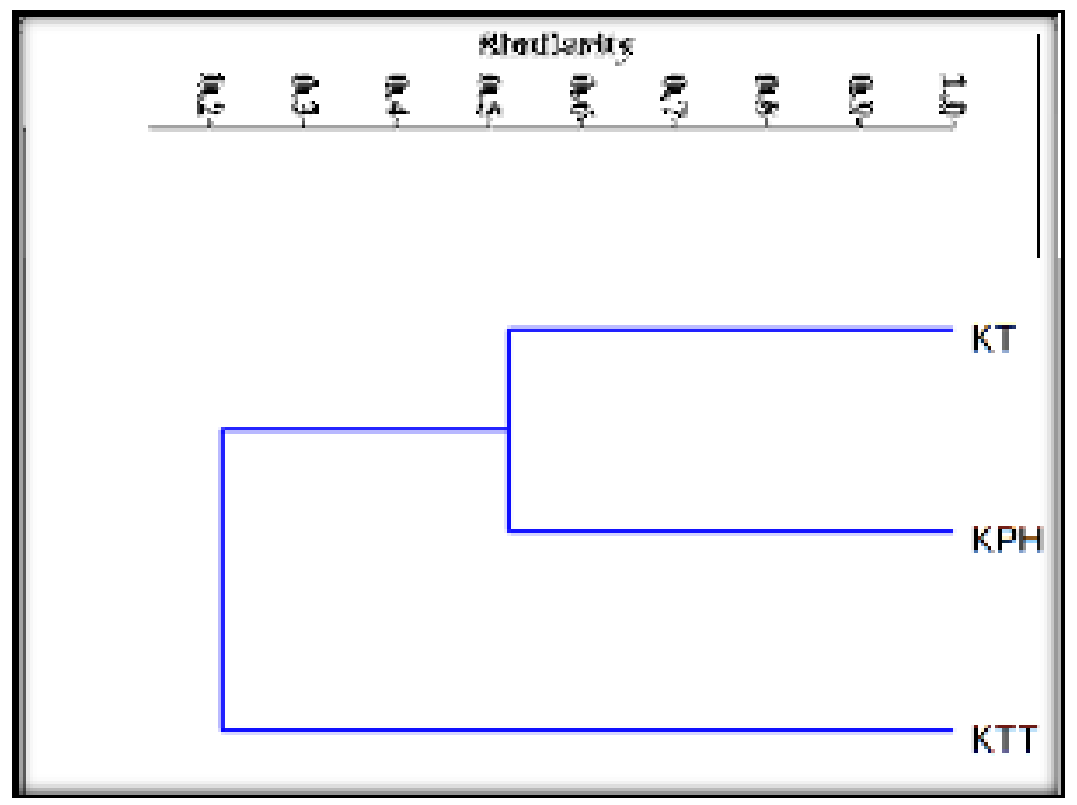

Gambar 4. Dendogram kesamaan komposisi komunitas kumbang Cerambycid antara habitat berdasarkan indeks kesamaan komunitas Bray-Curtis dengan metode paired-grup

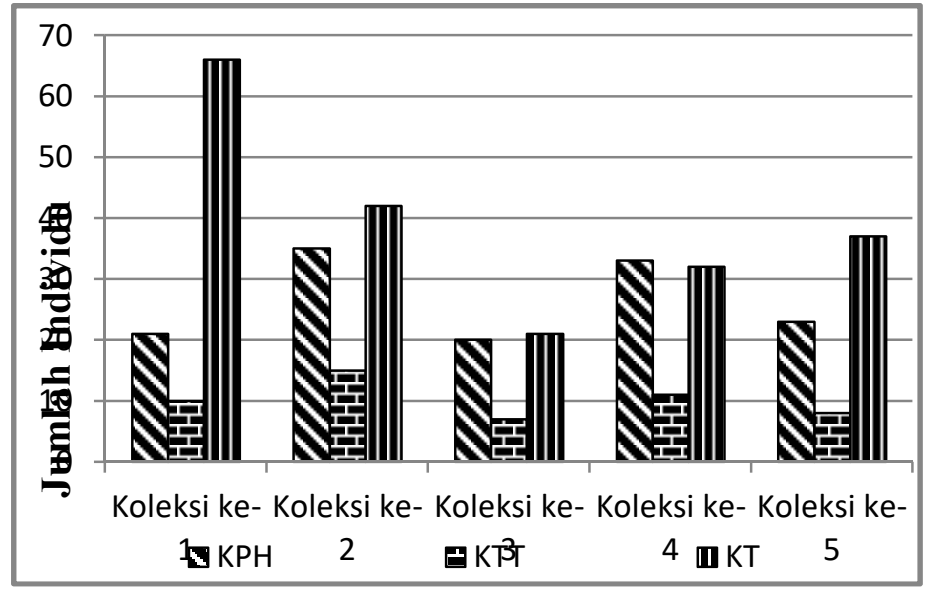

Gambar 5. Jumlah individu yang dikoleksi pada setiap pengabilan sampel.

\section{DAFTAR PUSTAKA}

Amirullah, Ariani, C., dan Suriana. (2014). Keanekaragaman

Cerambycidae (Coleoptera) kumbang

Kawasan Gunung Mekongga

Tinukari, Kecamatan Wawo, Kabupaten Kolaka Utara, Provinsi Sulawesi Tenggara. Biowallacea, 1(1), 16-24.
Bezark, L. G., 2015, A photographic catalog of the Cerambycidae of the new world. Versio March 2015. http://apps2. cdfa.ca.gov/PublicApps/plant/bycidDB/

Direktorat Jenderal Perkebunan. 2017, Statistik perkebunan indonesia 20152017. Direktorat Jenderal Perkebunan, Jakarta. 
Fahri, Atmowidi, T., and Noredjito, W.A., 2016, Diversity and Abundance of Cerambycid Beetles in the Four Major Land-use Types Found in Jambi Province, Indonesia. HAYATI Journal of Biosciences 23, 56-61.

Liendo, C. V., Herrera, B., Morillo, F., Sanchez, P., and Hernandez, J. V., 2010, Behavioral responses of Steirastoma breve (Sulzer) (Coleoptera: Cerambycidae) to host plant Theobroma cacao L., brushwood piles, under field conditions. Entomol. Zool, 45(3), 489-496.

Makihara, H., Noedjito, W. A., 2004, Longicorn beetles of Museum Zoologicum Bogoriense, identified by Dr. Gilmour,E.F. (1963) (Coleoptera: Disteniidae and Cerambycidae). Bull FFPRI. 3(I): 49-98.

Noerdjito, W. A., 2008, Struktur komunitas fauna kumbang antena panjang (Coleoptera; Cerambycidae) di kawasan Taman Nasional Gunung Ciremai. J Biologi Indonesia, 4(5), 371-384.

Noerdjito, W. A., 2010, Arti Kebun Raya Bogor bagi kehidupan kumbang antenna panjang (Coleoptera, Cerambicidae). J Biologi Indonesia, 6(2), 289-292.

Noerdjito, W. A., 2012, Dampak kegiatan manusia terhadap keragaman dan pola distribusi kumbang antena panjang (Coleoptera : Cerambycidae) di Gunung Salak, Jawa Barat. J Biol Indonesia. 8(1):57-69..

Sataral, M., Fahri., dan Atomowidi, T., 2017, Keanekaragaman Kumbang Antena Panjang (Coleoptera: Cerambycidae) pada Beberapa Perkebunan di Polokarto, Jawa Tengah. Journal of Natural Science 6(1), 90 - 99. 